\title{
MISEEVA : Set up of a transdisciplinary approach to assess vulnerability of the coastal zone to marine inundation at regional and local scale, within a global change context.
}

\author{
Charlotte Vinchon, BRGM, c.vinchon@brgm.fr \\ Nacima Baron-Yelles, LVMT, nacima.baron@enpc.fr \\ Emmanuelle Berthelier, SOGREAH, emmanuelle.berthelier@sogreah.fr \\ Cécile Hérivaux, BRGM, c.herivaux@brgm.fr \\ Sophie Lecacheux, BRGM,s.lecacheux@brgm.fr \\ Catherine Meur-Ferec, Geomer, Catherine.Meurferec@univ-brest.fr \\ Rodrigo Pedreros, BRGM, r.pedreros@brgm.fr \\ Hélène Rey-Valette, LAMETA, helene.rey-valette@univ-montp1.fr \\ Bénédicte Rulleau, REEDS, benedicte.rulleau@uvsq.fr
}

\begin{abstract}
MISEEVA (2008-2011) aims to assess coastal zone vulnerability to marine inundation by integrating the physical and socio-economical aspects at different temporal (2010, 2030 and 2100) and spatial (local to regional) scales. The Languedoc Roussillon (France) region was chosen as a pilot site, focusing on local sites from Villeneuve-lès-Maguelone to Carnon, in Hérault.

It required the development of a transdisciplinary methodology to enable transfers of knowledge and promote interdisciplinary iteration of methods throughout the project.

In 2030, sea level rise (SLR) should not exceed $0.07 \mathrm{~m}$ (IPCC, 2007). For 2100, SLR of 0.35m (A2 SRES scenario, GIECC 2007) and 1m (Rahmstorf, 2007, Grinsted et al, 2009), are both considered. As negligible changes in storminess are expected (IPCC, 2007, Déqué, 2007), historical storms are therefore used as references to simulate exceptional inundations, in 2010, 2030 and 2100.
\end{abstract}

Regional and local propagation of wind-generated waves and surges (wave set-up and atmospheric surge) are calculated using a chain of models and semi-empirical formulas. Then, maps of permanent, recurrent and exceptional inundations (due to SLR, tidal level, and surges) in 2010, 2030, and 2100 are drawn.

Socio-economy in 2030 is believed to follow the present day trend in Languedoc-Roussillon (demographic growth, urbanisation and tourist development). Socio-economic evolution in 2100 is quite unforeseeable: scenarios for 2100 are being built based on contrasted potential adaptation strategy scenarios

Designing a typology and valuation of present day assets help to value potential damages processes due to marine inundation on the coastal system at 2010, 2030 and 2100. Perception and response capacity knowledge to marine inundation risk is gained through residents, users and stakeholder surveys at the local site. 
Mixing physical and socio-economical approaches to evaluate the exposure of a territory to a hazard allows progression towards a systemic definition of vulnerability. Projection in the future points out the need to consider adaptation capacity as a main parameter of vulnerability evolution.

\section{Keywords :}

Marine inundation, coastal zone, global change, sea level rise, storms, surge, economic and social assets, assets valuation, adaptation capacity,

\section{Motivation of the project MISEEVA}

Analysis of historical data has underlined the existence of climate variation in the former decades (IPCC 2007). Climate modelling, considering an increase in gas emissions, leads the scientific community to anticipate a global warming, of various ranges in regards to the different socio-economic scenario built by the IPCC in 2000. Such warming should induce, between diverse consequences, a very likely sea level rise, and, with more uncertainty, a change in storminess (IPCC 2007)

Besides the fact that these drivers might increase existing coastal hazards (marine inundation and erosion, salted edge changes) and modify the shoreline configuration (Nicholls et al, 2007, Vinchon et al, 2009), the coastal zone, already heavily developed, is likely to undergo a higher demographic pressure in the coming decades and an associated economical and sociological evolution (as described for France by the report DATAR, 2004)

Therefore, the aim of the MISEEVAproject (2008-2011) is to study the coastal zone vulnerability to marine inundation in the coming century $(2010,2030,2100)$, in a global (climatic and socio-economic) change context, on a pilot region, at regional and local scales. The MISEEVA project gave the opportunity to gather a multidisciplinary project team, in order to elaborate a physical, economical and social assessment based on present day assessment and future climatic, and economic and adaptation hypotheses, then cross data to gain a systemic view of the coastal zone vulnerability to marine inundation.

The study is made on a pilot region (Languedoc Roussillon, France) with a local focus scale on five coastal communes (figure 1). This region present a long and narrow sandy shore, separated from back salted lagoon by narrow and low dunes locally called "lidos". Lagoons are linked to the sea by narrow channels, most of them artificialised, called "graus".

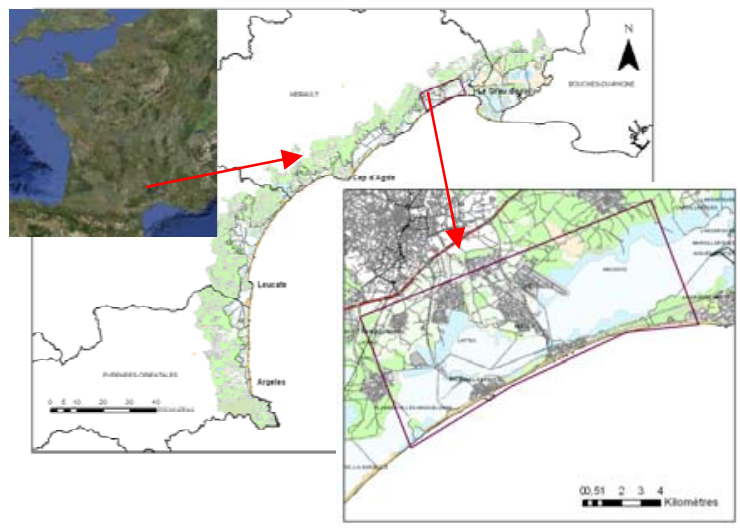

Figure 1 Location of the study at regional scale, (b) local scale 
The aim of the present paper, written before the end of the project, is to underline the respective inputs of the different disciplines and the necessary interactions to set up a transdisciplinary methodology and answer the objective of the project.

\section{Preliminary assumptions}

Preliminary assumptions were necessary in order to have, within the project team, common hypotheses and scenarios on climatic and socio-economic evolution at the chosen terms of 2030 and 2100. They were discussed, iterated and validated by the different actors of the project, at different milestones during the progress of the project.

\subsection{Climatic scenarios}

Models reported by IPCC (2007) give a sea level rise range, in 2100 , between $0.18 \mathrm{~m}$ and $0.59 \mathrm{~m}$, depending on the economic and social scenario established for IPCC 2000. Further publications (Ramstorf, 2007, Grinsted, 2009) considered that the exiting climatic models insufficiently consider the contribution of ice melting and proposed a higher sea level rise in 2100 (1m for Ramstorf, 1.20m for Grinsted). Hansen (2007) even proposes a range of $5 \mathrm{~m}$, considering past sea level rise during Pleistocene. In 2030, it is considered difficult to discriminate if the sea level rise is a result of climate change or natural climatic variation. However, in MISEEVA, the value of sea level rise in 2030 is interpolated, through IPCC 2007 curves, at a range of $0.07 \mathrm{~m}$. In 2100 (T2), two scenarios are considered: (i) T2a: the average value of $0.35 \mathrm{~m}$ SLR given by IPCC (2007) curves for the A2 socioeconomic scenario of IPCC 2000 (ii) T2b : the value, such as proposed by Ramstorf(2007), of $1 \mathrm{~m}$, commonly used in climatic scenarios (Nicholls and Lowe 2006, Nicholls and Tol, 2007).

If IPCC reports (2007) anticipate an increase of cyclonic tropical storms frequency, it is considered than there is still a high uncertainty on increase of temperate storminess. Regionalisation of models by the IMFREX project even anticipates (Déqué et al, 2003) a slight decrease of storminess on western Mediterranean Sea. Due to this uncertainty it is considered in MISEEVA that there will be no change in frequency or intensity of storms in the Languedoc Roussillon region. Therefore, modelling of marine inundation due to storms in 2030 and 2100 is done by considering a similar storm to the historical storm of November 1982, in Languedoc Roussillon, (high range storm which induced a high level of damages by marine inundation).

\subsection{Economic and demographic hypotheses}

The regional context of Languedoc Roussillon has been considered, starting by a nowadays assessment of social and economic trends : It shows a positive gross domestic product, but increasing demography due to migration, ageing population, partial pauperisation and precarious dwelling ; the economy is relying on importance of tourism (inducing high range of non permanent population) and a largely diverse and contrasted land use between seafront (urbanisation, tourism, commerce) and backshore (fisheries and shell, high biodiversity assets, decrease of agriculture versus urbanisation).

National and regional documents of planification help to anticipate a pursuit of present day trends in 2030, for demography and tourism economy, and a relative stability of other fields. (DATAR 2004, SRADT 2009).

However, no social or economic prediction can be done for 2100 , due to a high uncertainty on political, social and economic parameters. Two demographic and economic hypotheses 
are drawn : (i) a basic (though unlikely) "no-change" hypothesis where demography and economy would stay such as 2010, (ii) a "trend" hypothese, where demography shows a linear increase as the nowadays trend, associated to a stability of tourism and of other economic components but a deseasonalisation of tourism frequentation due to global warming (DATAR 2004).

\subsection{Perspectives of adaptation.}

The 2030 situation is likely to be very similar to the present day hazard of marine inundation $(0.07 \mathrm{~m}$ of sea level rise), on the coastal zone The increasing trend of demography and tourism activity is likely to further increase vulnerability of urbanized zones, mostly on lidos.

It has been considered that 2100 could only be foresight through contrasted and imagined situations, by considering the response of the coastal zone to different adaptation schemes. Several perspectives will be described : Extreme situations are proposed such as a denial of a possible change or, at the opposite, a generalized "hold-the line" choice, like it was done in the 20st century in Netherland (Delta Plan), or, at last, complete retreat from the coastal zone. Intermediate situations to these caricatured perspectives are also considered such as a composite adaptation with partial protection, managed retreat and/or "do-nothing" strategies, based in a ideal context ("perfect foresight" scenario as described by Michael, 2007) based on cost/benefice analyses on coastal zone assets and knowledge of the hazard parameters, or a partial protection of highest value assets (urban zones), composed with "donothing"on little urbanized or natural spaces, due to lack of funding.

The detailed consequences of such perspectives on physical aspects (shoreline position, extent of exceptional inundation,...) and socio-economical aspects (demography, dwelling evolution, touristic structures and uses, adaptation of agriculture, changes in biodiversity,...) will be one of the main results when crossing multidisciplinary approaches.

\section{Hazard assessment within climate change}

Three types of marine inundation are evaluated, considering that induced damages will be different,depending on the duration and the recurrence of inundation as well as the extent of inundated surfaces: (i) Sea level rise associated to climate change will induce a "permanent marine inundation". The total sea level considered includes the sea level rise for the different scenarios, the lowest astronomical tide and the set-up associated to a mean wave conditions. (ii) Although the tidal range in the Mediterrannean sea is rather small, the highest atmospherical tide can induce a "recurrent marine inundation" on lowlands near the coast at least twice a year. This case includes the sea level rise for the different scenarios, the highest astronomical tide and the set-up associated to mean wave conditions (iii) The "exceptional marine inundation" corresponds to reference past storm events such as november1982. The total sea level includes the sea level rise for different scenarios as well as the tide level, the atmospheric surge and wave set-up at the peak of the storm.

At regional scale, marine inundation hazard is approached through (i) nested models to simulate the wind generated waves, with the SWAN model developed by Delft hydraulic, (Booij et al ,2004), and the atmospheric surge and tide level, with the MARS model, developed at IFREMER, (Lazure and Dumas,2008). (ii) use of semi-empirical formulas (Stockdon, 2006) to calculate the set-up (surge due to waves'breaking) and the run-up (altitude reached by the swash). Modelisation of the 1982 storm, due to lack of measured 
data was done after validation of the model chain with better informed events (1997 and 2007). The total water level of inundation is then compared to the topographic data (MNT IGN) to deduce the areas concerned by marine submersion, and LIDAR topobathymetric data where available.

At that stage of the project, marine inundation has been determined at the regional scale for permanent recurrent and exceptional events (figure 2). More detailed modelisation of the surge on the shoreface is in process on the local site using high resolution topo-bathymetric data (LIDAR) and the model SURFWB (Marche et al, 2002) to calculate the set-up and runup onshore.

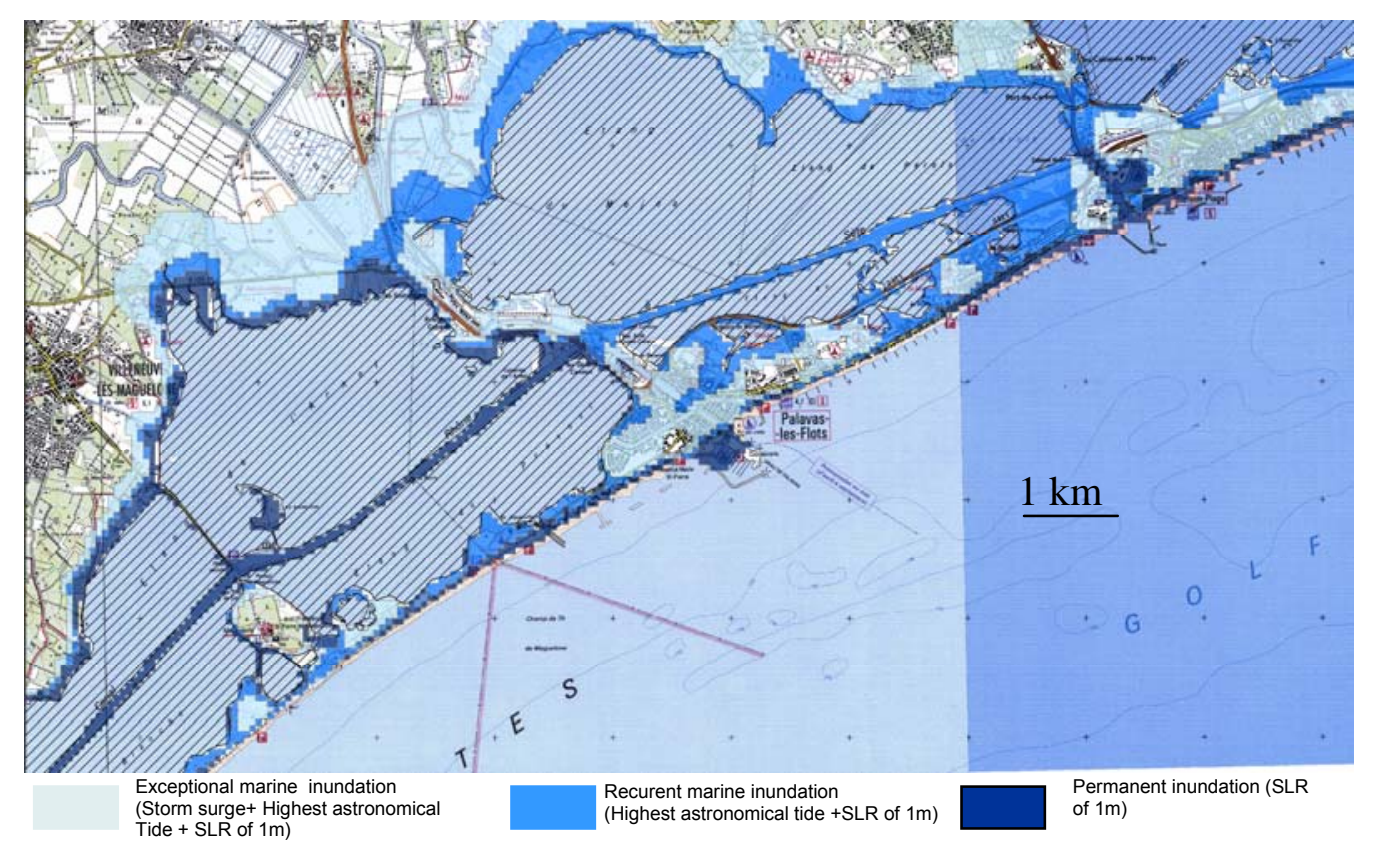

Fig 2 Marine inundation as modelled for 2100 for a sea level rise of $1 \mathrm{~m}$

Permanent and recurrent marine inundations in 2030 at regional scale show little differences with the 2010 situation, due to the likely anticipated low level $(0.07 \mathrm{~m})$ of sea level rise. Besides, the low spatial resolution of the regional DTM does not allow discriminating such change on a map On the contrary, in 2100 , the two sea level rise scenarios would have considerable impacts on permanently and recurrently inundated surfaces (figure 3 ).

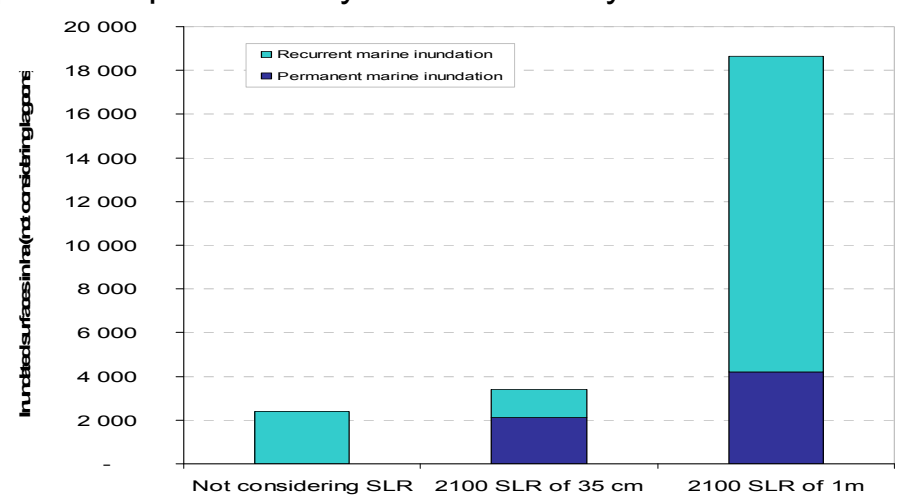

Fig.3 Potentially impacted surfaces in 2100 , considering the different scenarios of SLR 
Storm impact are also quite similar between present day and 2030 (figure 3), temporarily affecting beaches and penetrating the shore-face urban zone, and inducing inundation of lagoons periphery. Cumulated with high tide and SLR in 2100, it will induce inundation of most beaches surface and lidos inundations and overtopping .

However, these preliminary results have a high uncertainty level due to climatic change scenarios that still have to be confirmed in the coming years, approximation made on for the reference storm of 1982, due to the lack of in-situ data and the low resolution of the regional DTM ( $1 \mathrm{~m}$ in elevation, issued from IGN MNT50) used to propagate the inundation.

Therefore, crossing the values of water height leads to a strong approximation in surfaces evaluation, and the given values in this paper are only to be considered as range of values.

\section{Social, economic and environmental assessment of vulnerability}

Before evaluating potential damages at 2030 or 2100 terms in regards to global change, it was necessary to assess the 2010 social, economic and environmental components of the coastal territory than could be affected by marine inundation. For each component, intrinsic damage processes are analysed and damages indicators are being identified.

\subsection{Assets typology and valuation}

Inventory and valuation of different assets was made through different methodologies whether they are market or non-market.

The regional scale allowed quantifying present day surfaces of different land uses underlining heavy development linked to tourism with little space for natural environment and agriculture on the lidos, but important fisheries (shell and fish) and eco-systemic assets associated with the lagoons and surrounding wetlands. Up to $44 \%$ of drinkable and irrigation water resource comes from coastal aquifers groundwater.

Apart from some residual vineyards and salt flats on lidos, agriculture is mainly located on the northern banks of the lagoons (rice, arable lands, cattle and sheep breeding). The value of lagoons and associated wetlands, as well as lidos natural spaces is approached by their economic use and/or contingent eco-systemic value. Local analysis of dwelling distribution on the lidos (shore face) allowed to identify and map collectives or individual housing related to permanent or temporary occupation. Commercial stores are concentrated in town centres, on ground levels. Beaches value is considered both by market values of its uses, and the "contigent" value given by users. Tourism is indirectly approached as a resultant of valuating beaches use, associated hostelry and commerce. Main transport structures are present within the coastal zone: The Rhône to Sète channel and the railway from Sète to Agde, as well as numerous urban and non urban coastal roads.

\subsection{Potential intrinsic damages}

It was first necessary to define what kind of intrinsic damages could be encountered by each asset type, under marine inundation hazard, independently of its actual exposure and considering no adaptation measures would be taken.

Intrinsic damage on agriculture and wetlands depends on the duration and the recurrence of inundation. Salt can be responsible for seasonal or permanent destruction of culture, but can also lead to new biodiversity and eco-habitat distribution of wetlands or cultures. Where 
temperature increase might affect diversity and fishing modalities, permanent inundation should not affect fisheries and shell culture of the lagoons. Groundwater resource might be impacted in terms of salinity, affecting uses and quality of drinking and irrigation waters. Permanent inundation of urban zones will forbid residence and force commercial uses to retreat; when exceptional inundations can be overcome in urban zones depending on insurances and wealth of inhabitants and users. Inundation will also induce coastal squeeze, specifically on beaches. The coastal shoreface might loose its attractiveness, which could modify tourism structures and uses. Damages on power, water and transport nets might have a direct cost of replacement, and indirect impact on structures and functions.

At that stage of the project, one can foresee that those potential intrinsic damages have systemic links and may develop other indirect damages but there is not yet enough knowledge of the links to have an exhaustive approach of a "tree of damages".

The figure 4 gives the link between exposure and potential damage, in regards to land use, and evaluate the potentially inundated surfaces, at regional scale for 2100 T2a and T2b scenarios,. In the T2b scenario, a range of 4000 ha would be permanently lost, including existing beaches and natural lands, as well as 1000 ha of urbanised areas. Recurrent inundation would affect more that 4 times this surface, with a factor 3 for urbanised zones of the lidos and 5 for wetlands and agricultural land (northern bank of lagoons).

Exceptional inundations in 2030 and 2100 will reaches further lands on lidos (urban and natural spaces), could temporarly overtop the Rhône to Sète channel, inundate peropheric lands of the lagoons. It would then impact agricultural lands, wetlands and urban zones of the lido and northern bank. The impact on those assets will depend on the duration and height of the saline water contact with assets.

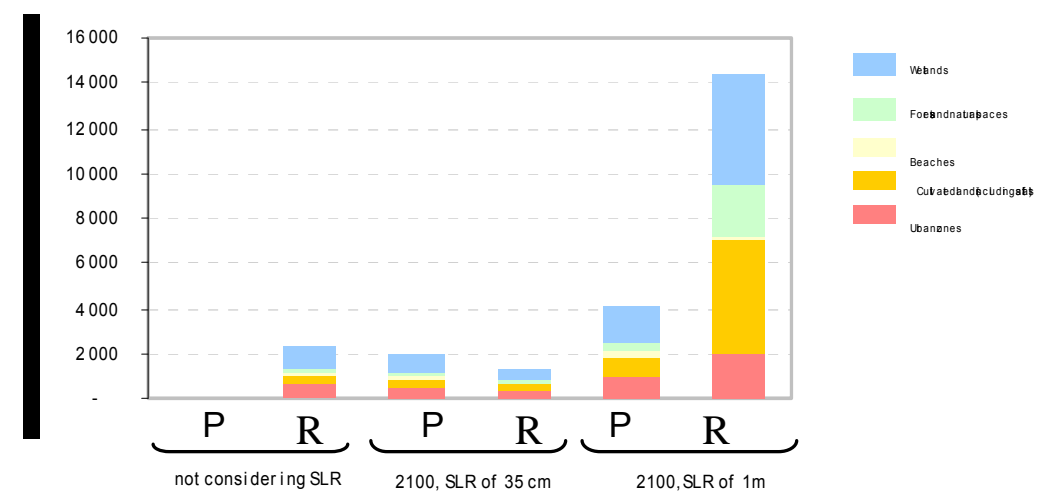

Fig 4.: Potential surfaces (ha) and related land uses permanently $(P)$ or recurrently inundated $(R)$ in 2100 , in regards to SLR scenarios

\subsection{Towards an indicator of damages}

As a result of the study of specific damages of assets exposed to marine inundation, a set of specific indicators are being identified and elaborated whenever the necessary data are available. They will be then evaluated in regards to the different adaptation perspectives and compiled to other data, to obtain a systemic view of coastal zone vulnerability to marine inundation. 


\section{Evaluation of adaptation capacity}

On the base of the above described analyses, both the hazard propagation data, and the processes of damages within the coastal territory were first described on a preliminary assumption of no adaptation. The present day adaptation capacity and risk consciousness is a necessary step before applying the "possible" adaptation perspectives to the coastal territory.

Both residents and users perception, and response capacity of coastal zone stakeholders, is evaluated. From this approach, elaboration of indicators of adaptation capacity is in process.

\subsection{Evaluation of public perception}

The capacity to adapt is studied through the perception of residents and users on the coastal zone. An survey of 563 permanent or temporary residents and shopkeepers was conducted in the local site communes. A complementary survey of 400 tourists and day-trippers was carried on, on the beaches, in summer 2009

The results of the residents' perception survey are presented by Meur-Ferec et al (2010) in this same volume (Littoral 2010 congress proceedings). A work is in process to identify adaptation capacity indicators from interpretation of these results.

\subsection{Public policies in risk management}

The analysis of regional or national strategic documents (SRADT,2009, Plan Climat pour le Languedoc Roussillon, 2009) shows that the consciousness of a coastal vulnerability due to climate change is still to be developed, and might not be sufficiently considered in present day or coming decades planification. Interviews of public stakeholders implied coastal risk is in process and should complete this analysis

\section{Conclusions}

At that stage of the project MISEEVA, numerous data have been collected in the different disciplines of vulnerability evaluation of the coastal zone to marine inundation.

The transdisciplinary approach of MISEEVA leads to associate physical and socio-economic data, to get common vocabulary and concepts within the project and discriminate within the process of hazard propagation, the main factors of damaging. A common validation and iteration of assumptions has been necessary at different milestones of the project to set up the preliminary climatic scenarios, the definition of marine inundation propagation in links with return periods and therefore induced damages and the construction and analysis of demographic and economic hypotheses and adaptation perspectives. The aggregation of the multidisciplinary results should allow gaining a vulnerability indicator that will be applied at the different terms and/or perspectives.

It has been underlined that the study is accompanied by a high level of uncertainty, due to initial data themselves (topography) and preliminary hypotheses from which climatic and economic scenarios have been built. However, despite a present day limited knowledge of future, building of physical, socio-economic and adaptation hypotheses allows to draw a picture of the extent, return periods and impact of marine inundation and its specific impact on assets. If it is not yet possible to elaborate damage functions for all type of assets, it underlines which is likely to be damaged and where, and gives a relative quantification of the affected surfaces. 
This project is to be completed in the coming year to complete the approach by a systemic knowledge of vulnerability to marine inundation of the coastal territory, in a changing context and give a sight on different "possibles" in the coming century

\section{Acknowledgements}

MISEEVA was built within the ANR VMC 2007 program and is financially supported by ANR; with participation of BRGM and SOGREAH for their specific actions The MISEEVA partnership associated the action of BRGM (coordinator), SOGREAH, and the university laboratories of LAMETA, MESHS, LVMT and EPOC. Special thanks are addressed to the benevolent participation of the REEDS and I3M laboratories.

The transdisciplinary objective needed a strong interaction within the project and the authors wish to thank Y. Balouin (BRGM), J.C. Charles (LAMETA), E. Delvallée (BRGM), H. Flanquart (MESHS), M. Garcin (BRGM), A.P. Hellequin (MESHS) Y. Krien (BRGM), L.Kuhfuss (LAMETA), G. Le Cozannet (BRGM), L. Maton (BRGM), F. Nathan (SOGREAH..), B Poisson (BRGM), M. Yates-Michelin (BRGM), A..L.Agenais (BRGM)

Thanks to F. Marche (I3M) and P. Bonneton (EPOC) for giving access to SURF Wb.

Historical storms and marine inundations data were kindly open to the MISEEVA project by the Direction Régionale de l'Environnement, l'Aménagement et le Logement.(DREAL) of Languedoc-Roussillon. MISEEVA was also given access to LIDAR topobathymetric data of the local site (co- property DREAL/LR, Conseil Général de l'Hérault and EIDMediterrannée); Thanks to $C$. Vanroye (DREAL) in giving access to these data.

\section{References}

Booij, N., Haagsma, I.J.G., Holthuijsen, L.H., Kieftenburg, A.T.M.M., Ris, R.C., van der Westuysen, A.J., Zijlema, M., 2004. Swan Cycle III version 40.41. User's Manual,115 pp.

Conseil Régional du Languedoc Roussillon, 2009. Schéma Régional d'aménagement et de développement durable du territoire 526 p. http://www.laregion.fr/69-amenagement.htm

Conseil Régional du Languedoc Roussillon, 2009. Plan climat-Région Languedoc Roussillon 130 p. http://www.laregion.fr/2645-plan-climat.htm

Délégation à l'Aménagement du Territoire et à l'Action Régionale (DATAR) , 2004, Construire ensemble un développement équilibré du littoral. La Documentation française, Paris 155p

Gibelin, A.L. and Déqué, M., 2003 : Anthropogenic climate change over the Mediterranean region simulated by a global variable resolution model. Climate Dyn., 20, 327-339

Grinsted A., Moore $Æ$ J. C., Jevrejeva S, 2009, Reconstructing sea level from paleo- and projected temperatures 200 to $2100 \mathrm{AD}$, Climate Dynamics.

Hansen, J. E.,2007, Scientific reticence and sea level rise, Environmental research letter 2' April-June 2007), http://www.iop.org/EJ/article/1748-9326/2/2/024002/erl7 2 024002.html

IPCC, 2000, Emission scenarios (including Summary for Policymakers), A Special Report of IPCC Working Group III, $3^{\text {rd }}$ assessment . ISBN: 92-9169-113

IPCC, 2007, 4th Assessment Report, Climate change 2007: The physical Science Basis. Contribution of Working Group I to the Fourth Assessment report of the Intergouvernmental 
Panel on Climate Change [Solomon S., D. Qin, M. Manning, Z. Chen, M. Marquis, K.B. Averyt, M. Tignor and H.L. Miller (eds.)]. Cambridge University Press, Cambridge, UK, and New York, USA., 2007

Lazure, P., Dumas, F., 2008. An external-internal mode coupling for a 3D hydrodynamical model for applications at regional scale (MARS). Advances in Water Resources 31, pp233250.

Marche F., Bonneton P, Fabrie P., Seguin N. 2007, Evaluation of well-balanced borecapturing schemes for 2D wetting and drying processes (avec), Int. J. Num. Meth. Fluids, 53(2007),pp 867-894

Meur-Férec C. , Flanquart H., Hellequin A.P., Rulleau B., 2010, Risk perception, a key component of systemic vulnerability of coastal zones to erosion-submersion. Case study on the French Mediterranean coast., this volume : Littoral 2010 London conference proceedings

Michael J.A., 2007, Episodic flooding and the cost of sea level rise, Ecological economics, vol 63 pp149-159.

Nicholls, R.J., and Lowe J.A., 2006: Climate stabilisation and impacts of sea-level rise. Avoiding Dangerous Climate Change, H.J. Schellnhuber, W. Cramer, N. Nakićenović, T.M.L. Wigley and G. Yohe, Eds., Cambridge University Press, Cambridge, 195-202.

Nicholls R.J., and Tols R. 2007, Regional to global implications of sea level rise: an analysis of the SRES scenarios, Philosophical Transactions of the Royal Society..

Rahmstorf, S., 2007, A semi-empirical approach to projecting future sea-level rise; Science, VOL $215,19^{\text {th }}$ January 2007, p. 368,369

Stockdon, H.F., Holman R.A., Howd P.A., Sallenger A.H., 2006. Empirical parameterization of setup, swash, and run-up, Coastal Engineering, 53(7), pp. 573-588.

Vinchon C., Aubie S., Balouin Y., Closset L., Garcin M., Idier D., Mallet, C. 2009, Anticipate response of climate change on coastal risks at regional scale in Aquitaine and Languedoc Roussillon (France)Ocean \& Coastal Management 52 (2009) pp 47-56 